\title{
Sport Medicine Diagnostic Coding System (SMDCS) and the Orchard Sports Injury and Illness Classification System (OSIICS): revised 2020 consensus versions
}

\author{
John W Orchard (1) , 'Willem Meeuwisse, ${ }^{2}$ Wayne Derman ำ , 3,4

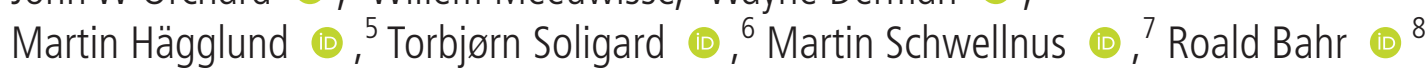

- Additional material is published online only. To view please visit the journal online (http://dx.doi.org/10.1136 bjsports-2019-101921).

For numbered affiliations see end of article.

Correspondence to Dr John W Orchard, School of Public Health, University of Sydney, Sydney, NSW 2006, Australia;

john.orchard@sydney.edu.au

Accepted 14 February 2020 Published Online First

5 March 2020
Check for updates

(C) Author(s) (or their employer(s)) 2020. No commercial re-use. See rights and permissions. Published by BMJ.

To cite: Orchard JW Meeuwisse W, Derman W, et al. Br J Sports Med 2020:54:397-401.

\section{ABSTRACT}

Coding in sports medicine generally uses sports-specific coding systems rather than the International Classification of Diseases (ICD), because of superior applicability to the profile of injury and illness presentations in sport. New categories for coding were agreed on in the 'International Olympic Committee (IOC) consensus statement: Methods for recording and reporting of epidemiological data on injury and illness in sports 2020.' We explain the process for determining the new categories and update both the Sport Medicine Diagnostic Coding System (SMDCS) and the Orchard Sports Injury and IIIness Classification System (OSIICS) with new versions that operationalise the new consensus categories. The author group included members from an expert group attending the IOC consensus conference. The primary authors of the SMDCS (WM) and OSIICS (JO) produced new versions that were then agreed on by the remaining authors using expert consensus methodology. The SMDCS and OSIICS systems have been adjusted and confirmed through a consensus process to align with the IOC consensus statement to facilitate translation between the two systems. Problematic areas for defining body part categories included the groin and ankle regions. For illness codes, in contrast to the ICD, we elected to have a taxonomy of 'organ system/region' (eg, cardiovascular and respiratory), followed by an 'aetiology/ pathology' (eg, environmental, infectious disease and allergy). Companion data files have been produced that provide translations between the coding systems. The similar structure of coding underpinning the OSIICS and SMDCS systems aligns the new versions of these systems with the IOC consensus statement and also facilitates easier translation between the two systems. These coding systems are freely available to the sport and exercise research community.

\section{INTRODUCTION}

Sports injury and sports-related illness classifications have - to date - only had minimal overlap with classification of disease used in healthcare. Broadly speaking, the focus of medicine is on mortality (causes of death) and morbidity (years of life spent living with a disease); non-communicable disease dominates both categories, causing $71 \%$ of all deaths worldwide. ${ }^{12}$ In the young adult, injury is a prominent cause of death, ${ }^{1}$ chiefly through motor vehicle accidents, suicide and, in some countries, homicide.
Injuries and illness related to sports, on the other hand, rarely cause death, but are common and can result in significant morbidity. Preventing sportsrelated injury and illness has become an important focus in the evolution of sport and exercise medicine. Injury and illness can limit the ability to play sport and be physically active, a key lifestyle component to reduce the burden of non-communicable disease. ${ }^{3}$

Sports injury and illness surveillance was only first undertaken in the 1960s and 1970s in isolated projects $^{4-6}$ and in more extensive studies starting in the 1980s. ${ }^{7-10}$ At the time, the International Classification of Diseases (ICD) was in its ninth Edition. ICD is the foundation for the identification of health trends and statistics globally, and the international standard for reporting diseases and health conditions. However, ICD was not suitable to classify sports-related injuries or illnesses, as it is initially based on causes of death and then includes major causes of chronic morbidity and hospital admission.

The recently released version of ICD-11 (which will become the official version in 2022) is more comprehensive and has an applicable code for almost all sporting injuries and illnesses. From a sporting perspective, it still suffers from the dual problems of having too many codes irrelevant to sport and not enough sports-specific injury/illness codes. To cite a common example, injuries to the hamstring muscle group are the most common in several sports, ${ }^{11-15}$ but do not have a unique ICD code. From the perspective of researchers investigating causes of death, major morbidity or hospital admission, hamstring injury would be of little consequence and therefore can be classified in ICD within a broader category of nonspecific soft tissue conditions of the posterior thigh. However, from a sporting perspective, if hamstring muscle injury is the number one reason players miss a game, then it warrants a well-defined injury code in a sporting injury classification system.

\section{Goals of sports injury and illness classification systems}

Injury and illness classification systems are used in sports medicine to:

1. Accurately classify and group diagnoses for research or reporting, allowing easy grouping into parent classifications for summary, so that injury and illness trends can be monitored over time. In addition, injury or illness incidence or prevalence can be compared between groups (eg, 
different teams, leagues, sports and sexes), potentially leading to risk factor and prevention studies.

2. Create databases from which cases can be extracted for indepth research on specific types of injuries and illnesses.

3. Facilitate comparative studies between different research projects with the use of common coding systems.

\section{Early development of sports injury and illness classification systems}

In 1988, a landmark supplement on injury surveillance was published by the American Journal of Sports Medicine. ${ }^{16} 17$ This was the first major publication to clearly state that an injury and illness surveillance system had multiple components, including 'Definition of a cohort/population', 'Definition of an injury', 'Injury classification (coding/diagnosis)', 'Injury mechanism', 'Injury severity and other outcome measures'. ${ }^{16} 17$ This supplement also included the first sports injury-specific coding system, the National Athletic Injury/Illness Reporting System Medical Terminology Codebook. ${ }^{18}$ However, an obstacle was that the authors made it clear that the use of the codes was restricted by copyright.

In the early 1990s, in Australia and Canada, two new diagnostic coding systems were developed simultaneously and these are the most widely used systems in the world today. They provide open access so researchers can use them free of charge (but with acknowledgement).

These systems are the Sport Medicine Diagnostic Coding System (SMDCS, also known as 'Calgary codes') and the Orchard Sports Injury Classification System (OSICS). Both are based on initial codes to represent body region and further codes to represent tissue type and pathology. As sports epidemiology traditionally has mainly focused on injury, less on illness, both coding systems reflect this, with fewer codes for illness than injury. The ICD-11, with its 55000 codes, probably contains too many rare diagnoses to be practical in a sporting setting. For comparison, SMDCS and OSICS have generally had up to 750-1500 codes in each version.

\section{Development of the SMDCS}

The SMDCS was developed at the University of Calgary in 1991. The fundamental basis for this was anatomical with three tiers of classification: body area, tissue type and then pathology type. Version and revision control has been maintained at the University of Calgary generally without publication of different version numbers, with users able to freely receive the most up-to-date version by request from the authors.

\section{Development of the OSICS, to become Orchard Sports Injury and Illness Classification System including Illness}

The OSICS was developed in 1992 and it provided the codes for a study that examined the incidence of injury at the elite level of football in Australia. ${ }^{19}$ The taxonomy for OSICS was very similar to SMDCS (although that they were developed independently). OSICS also classified by body area initially, and then injury type (including tissue type) as a combined second character. Versions of OSICS that have been published include a 1993 version, ${ }^{20}$ a 1995 version $^{21}$ and then freely available for download as versions 7, 8 and 9. OSICS was modified into version 10 in 2007, ${ }^{22}$ this included a major expansion of illness diagnoses. Other developments included more codes denoting 'unknown/unspecified' injury types, allowing easier use by nonexpert coders. However, some users remarked that the expansion of codes made OSICS10 less easy to navigate than the

\section{Box 1 Coding files}

The following tools are available as appendices:

Online supplementary appendix 1: SMDCS V.2 (new version to update previous SMDCS), based on the new IOC consensus injury and illness categories, including translations to and from both the old version and ICD-11.

Online supplementary appendix 2: OSIICS V.13 (new version to update both OSICS 9 and OSICS 10), based on the new IOC consensus injury and illness categories, including translations to and from both the older versions and ICD-11

Online supplementary appendix 3: Translations between (to and from) SMDCS 2 and OSIICS 13, presented by categories in the IOC consensus statement

ICD, International Classification of Diseases; OSIICS, Orchard Sports Injury and IIIness Classification System; OSICS, Orchard Sports Injury Classification System; SMDCS, Sport Medicine Diagnostic Coding System.

earlier versions for the standard injury codes. The new version arising from this paper will be called Orchard Sports Injury and Illness Classification System (OSIICS) (including a second 'I' for Illness), with generally three-character codes for injuries and four/five-character codes for illness.

\section{Purpose}

This project was initiated based on a consensus meeting convened in October 2019 by the International Olympic Committee (IOC) to produce an updated set of recommendations for sports epidemiology, drawing on recent methods developments and the experience of a group of scientists working in the field of sports injury and illness surveillance. ${ }^{23}$ The goal of the consensus meeting was to provide hands-on guidance to researchers on how to plan and conduct data collection and how to report data from studies and further encourage consistency across studies. The IOC consensus statement is published as a separate report. ${ }^{23}$

Since a key component of epidemiological research is diagnostic coding, a subgroup of the IOC consensus group updated SMDCS and OSICS with new versions, and developed translations between these two systems, past versions and ICD-9/10/11 codes (box 1). The purpose of this exercise was to allow researchers to code sports injuries and illnesses and to unify data categories between systems. These tools are available as online supplementary appendices 1-3.

\section{Methods considerations}

Formation of consensus core group

This core group included members of the expert group for the IOC consensus meeting; the primary authors of OSICS (JO) and SMDCS codes (WM) led the process.

The core group aimed to achieve consensus methodology. The lead authors for each of the injury and illness streams tried to present an expert view of 'best fit' categories in the injury and illness streams that were acceptable to the other members of the expert core group.

\section{Specific methods for injury stream}

Body areas and injury types from the main consensus were initially compared between OSICS and SMDCS codes to look for agreement between these two coding systems. The preliminary consensus definitions were then tested by the lead authors for OSICS (JO) and SMDCS codes (WM) to check compatibility 
with these systems. The consensus definitions were then further reviewed by the expert group after compatibility checks with OSICS/SMDCS.

\section{Specific methods for illness stream}

With respect to the Illness stream, it was thought that neither of OSICS, SMDCS nor the ICD-10/ICD-11 provided the same degree of refinement as the injury codes in the context of athlete care. It was recommended by WD that we review the literature of presentation of sporting illnesses (in tables of previous publications) ${ }^{24-27}$ and use these presentations as a way to best recategorise illness according to, first, the system involved and second, the aetiology of illness. However, the recommended categories from the ICD-10/ICD-11 were also taken into consideration.

\section{Distinction between injury and illness}

The distinction between 'injury' and 'illness' (occasionally referred to as 'medical') codes is defined by the IOC consensus statement ${ }^{23}$ as follows: injury is tissue damage or other derangement of normal physical function due to participation in sports, resulting from rapid or repetitive transfer of kinetic energy. Illness is a complaint or disorder experienced by an athlete, not related to injury. Therefore, when revising the codes, an 'injury' code was the most appropriate if the aetiology was biomechanical. If not (ie, the condition had a physiological aetiology), then an 'illness' code was more appropriate.

Some examples of this distinction where we felt the distinction was clear between injury and illness using these definitions were:

- Concussion is an injury, whereas migraine is an illness.

- A corneal laceration is an injury, whereas glaucoma is an illness.

- A traumatic liver contusion is an injury, whereas hepatitis is an illness.

- A localised skin abrasion or blister from repetitive friction is an injury, whereas a fungal skin infection is an illness.

- Osteoarthritis (if post-traumatic) is an injury, whereas rheumatoid arthritis is an illness.

There is a considerable overlap between certain conditions that could equally be considered illnesses or injuries depending on the context, even despite our definition. Rheumatologists typically view osteoarthritis and conditions like plantar fasciitis to be illnesses, whereas sports medicine clinicians view them as injuries. Neither of these positions is right or wrong, as the aetiology is part biomechanical and part physiological.

The diagnosis that led to the most controversy was drowning, a rare condition in the sports medicine context. Drowning is certainly considered an injury by the general medical community, hence we have provided injury codes for drowning. However, it is another condition that has both biomechanical contribution (inability to get/keep one's head above water) and physiological contribution (water entering the lungs).

With our distinction reliant on biomechanical aetiology, our recommended split immediately differs from ICD-10/11. In the ICD, there is a section (XIX in ICD-10 and 22 in ICD-11) for 'injury, poisoning and certain other consequences of external causes'. However, the ICD requires a condition to have been of immediate onset/consequence in order to be considered part of this section. An acute fracture from instantaneous trauma is considered an external injury by the ICD, while a stress fracture (from repetitive forces) is not considered an injury (by ICD) but a disease of the musculoskeletal system. We considered this distinction to be sub-optimal for sport and we defined an injury as having a biomechanical aetiology, irrespective of whether it is of sudden onset or gradual onset.

\section{Structure of coding systems for injury and illness}

Taking into account the previously existing structure of OSICS and SMDCS, we agreed that injury codes needed a threedimensional categorisation, one being by 'body part', the second 'tissue type' and the third 'pathology type'. For example, a case of Sever's disease would be classified in the categories 'foot', 'bone' and 'physis injury'. The major structural difference between the new OSIICS and SMDCS for the injury codes will remain that SMDCS will have two distinct numeric indicators for 'tissue type' and 'pathology type' whereas OSIICS will have a second (alpha) character for the injury codes that denotes both tissue and pathology (see table 5 in the IOC consensus paper). ${ }^{23}$

In contrast to illness codes in existing coding systems, including ICD, we agreed that illness codes should have a two-dimensional classification. The first part of the classification for illness codes represents a 'organ system/region' (eg, cardiovascular and respiratory) and the second part 'aetiology/pathology' (eg, environmental, infectious disease and allergy). A case of otitis media is coded as 'otological' and 'infection'. This is analogous to the subclassification of the injury codes.

We argue that this method of classification for the illness codes improves the taxonomy. The most compelling argument is that the most common illness in sports (the illness equivalent of hamstring injury) is an acute upper respiratory tract infection. Using ICD categories, it is unclear whether this should be categorised as an infectious disease or as a disease of the respiratory system. It is clearly both, and it is suboptimal and confusing to need to choose between the two. The Venn diagram of infectious diseases and respiratory system diseases overlaps, and a classification system should allow dual membership in both of these categories. The tiered systems in the new versions of SMDCS and OSIICS accommodate this condition with the system (respiratory) and aetiology (infection).

The main consensus categories are presented as table 4 (body areas) and table 5 (tissue types and pathologies) for injuries and table 7 (organ system/region) and table 8 (aetiology) for illnesses in the IOC consensus paper. ${ }^{23}$

\section{Challenging injury definitions}

Wherever possible, we tried to define body areas anatomically as either joints or segments. However, exceptions were made based on common clinical presentations in sport. For example, the hip and groin area is a combination of joint and part of segment. We recognised that it is difficult clinically to differentiate pain anatomically in this region (just as it is for low back pain). If we split this region into hip joint, pelvis and thigh as three separate areas, there would be very poor reliability between different clinicians and therefore classifications in studies.

We based our classification on the Doha consensus statement on groin pain, ${ }^{28}$ and specified that this region should include hip joint, proximal adductor and pubic symphysis, inguinal and femoral canals and iliopsoas. Because of the pre-existing structure of both SMDCS and OSICS, we also included lateral hip structures in the hip/groin region. The definition of the hip/groin region finally included: hip joint, pubic bone, proximal adductors, proximal hip flexors, gluteal muscles, inguinal and femoral canals, trochanteric region, neck of femur, body of ischium and majority of ileum including iliac crest and external genitalia.

This helped to define nearby regions as: 
- Thigh: Includes the ischial tuberosity (hamstring origin) and distal adductors and other thigh muscles from the level of below lesser trochanter (externally, approximately $5 \mathrm{~cm}$ below the pubic symphysis and approximately where the sartorius meets the gracilis), and femur beyond the lesser trochanter down to the capsule of the knee joint.

- Abdomen: All musculotendinous tissue above the inguinal canal/ligament (obliquus, rectus and transversus abdominis) and all internal abdominal organs below diaphragm.

- Lumbosacral spine: Starts at L1 and finishes laterally at the transverse processes, includes sacrum, coccyx, sacroiliac joints and the ileum immediately adjacent to the posterior superior iliac spine.

The other problematic body area was around the ankle and heel. The ankle was not considered to have an anterior boundary. Superiorly, the lateral malleolus, medial malleolus and inferior tibiofibular syndesmosis were considered to be part of the ankle. Posteriorly, the Achilles tendon and its insertion were considered to be part of the lower leg (not ankle). However, the talus, subtalar joint and related tendinous structures immediately posterior to the ankle were considered to be part of the ankle. The calcaneus and plantar heel were considered part of the foot.

The distinctions in this area were made using similar logic to the Doha consensus groin statement in terms of grouping conditions that have overlapping clinical presentations. We did not wish to split the distal calf and Achilles tendon, so made the decision that Achilles tendon was part of lower leg. However, because the entity known as 'posterior impingement of the ankle' includes bony (posterior talus/os trigonum) and tendinous ankle structures (flexor hallucis in particular), these were included as part of the ankle. A consequence of this is that tibialis anterior, tibialis posterior, flexor hallucis longus, extensor and flexor digitorum and the peroneal muscles and tendons are all part of three regions: lower leg (for their origins and muscular portions), ankle (for their mid-tendons in proximity to the ankle joint) and foot (for their insertions).

Finally, we emphasise that there that there is room for a sport to make slight variations to the recommended body part categories. We expect that subsequent consensus statements on specific sports will provide recommendations on suitable, standard formats for each sport, to facilitate direct comparison of data on key injury types from studies on the same sport. For example, a sport such as rock climbing, where hand injuries are very common, may want to report the thumb as a separate region to the fingers. Alternatively, when reporting injuries from a $10 \mathrm{~km}$ fun run event, it seems reasonable to merge parts of the upper limb into broader categories (eg, shoulder and upper arm in a single category together) if the injury rates for these body parts are low.

\section{Challenging illness definitions}

We considered the sleep-wake system to be an environmental pathology type rather than separate body system as judged by ICD-11 (athletes commonly present with jet lag when travelling internationally). We also separated dental problems from the gastrointestinal system. We decided that the thermoregulatory system should be considered a separate body system because abnormalities in this system (eg, hyperthermia or hypothermia) are common clinical presentations in sports medicine.

However, some decisions were made in keeping with ICD. We merged the nose and throat and the upper respiratory system so that the nose, throat, sinuses and larynx are considered part of the respiratory system. If split by medical specialty, then the ear belongs with nose and throat, but ear conditions are diagnostically very distinct. We felt that, as the nose and throat overlap significantly with the upper respiratory system, they needed to be merged. Similarly, the presentation overlap in athletes between urinary tract infections (urological) and sexual transmitted infections (genital) is significant; therefore, they were merged.

\section{CONCLUSIONS}

Sports injury and illness require a distinct classification, with the ICD not sufficiently comprehensive for the sporting scenario, yet also with too many non-sporting diagnoses. The similar structure of coding underpinning the OSIICS and SMDCS systems has allowed us to align the diagnostic coding systems with injury and illness type categories recommended by the IOC consensus statement: Methods for recording and reporting of epidemiological data on injury and illness in sports. ${ }^{23}$ The new versions of SMDCS (V.2) and OSIICS (V.13) (online supplementary appendices 1 and 2) have approximately 1000 and 1500 codes, respectively, and their common structure now facilitates much easier translation between them. We have attached translation files as Appendices \#1-3. We also feel that both systems have developed improved diagnostic coding categories for illnesses based on body system/pathology type structure. The OSIICS and SMDCS can be used freely, providing they are referenced appropriately.

\section{Appendices}

It is expected that the Appendix files will be updated occasionally. In particular, it is likely that slightly revised versions of the coding systems will be uploaded in late 2020 after the initial versions of the new systems have been used live for the first time.

\section{Author affiliations}

${ }^{1}$ School of Public Health, University of Sydney, Sydney, New South Wales, Australia ${ }^{2}$ Sport Injury Prevention Research Centre, Faculty of Kinesiology, University of Calgary, Calgary, Alberta, Canada

${ }^{3}$ UCT/MRC Research Unit for Exercise Science and Sports Medicine, Department of Human Biology, University of Cape Town, Cape Town, South Africa

${ }^{4}$ International Olympic Committee Research Centre, University of Cape Town, Cape Town, South Africa

${ }^{5}$ Medical and Health Sciences, Linköping University, Linköping, Sweden

${ }^{6}$ Medical and Scientific Department, International Olympic Committee, Lausanne, Switzerland

${ }^{7}$ Sports, Exercise, Medicine and Lifestyle Research Institute (SEMLI), University of Pretoria, Pretoria, South Africa

${ }^{8}$ Department of Sports Medicine, Oslo Sports Trauma Research Center, Norwegian School of Sport Sciences, Oslo, Norway

Correction notice This article has been corrected since it published Online First. The abbreviation in the article title has been corrected.

Twitter John W Orchard @DrJohnOrchard, Wayne Derman @WDerman, Martin Hägglund @MHgglund, Torbjørn Soligard @TSoligard and Roald Bahr @RoaldBahr

Acknowledgements Authorship was restricted to those authors who participated in teleconferences and/or review of this paper prior to the IOC consensus meeting. The following IOC consensus group members people assisted extensively with reviewing some of the concepts and manuscript during or after the meeting: Babette Pluim, Simon Kemp, Karim Chamari, Ken Quarrie, Bruce Reider, Astrid Junge, Caroline Finch, Karim Khan. All other IOC consensus group members (reference 23) are also acknowledged. The following people assisted in review of OSIICS between the most recent publication of OSICS 10 and the current publication: Ian Shrier, Etienne du Preez, Katherine Rae, Olivier Materne, Eric Besenius, Gil Rodas, Lluis Til, Nirmala Perera, Lauren Fortington. Anna Saw assisted with coding translations between OSIICS and SMDCS and the ICD11.

Contributors All authors were part of both the IOC consensus conference and preliminary teleconferences prior and made substantial contributions. There were many minor contributors who have been acknowledged.

Funding The authors have not declared a specific grant for this research from any funding agency in the public, commercial or not-for-profit sectors.

Competing interests None declared. 
Patient consent for publication Not required.

Provenance and peer review Not commissioned; externally peer reviewed.

ORCID iDs

John W Orchard http://orcid.org/0000-0003-3530-1711

Wayne Derman http://orcid.org/0000-0002-8879-177X

Martin Hägglund http://orcid.org/0000-0002-6883-1471

Torbjørn Soligard http://orcid.org/0000-0001-8863-4574

Martin Schwellnus http://orcid.org/0000-0003-3647-0429

Roald Bahr http://orcid.org/0000-0001-5725-4237

\section{REFERENCES}

1 GBD 2016 Disease and Injury Incidence and Prevalence Collaborators. Global, regional, and national incidence, prevalence, and years lived with disability for 328 diseases and injuries for 195 countries, 1990-2016: a systematic analysis for the global burden of disease study 2016. Lancet 2017;390:1211-59.

2 WHO. Noncommunicable diseases country profiles 2018, 2018: 223.

3 Matheson GO, Klügl M, Engebretsen L, et al. Prevention and management of noncommunicable disease: the IOC consensus statement, Lausanne 2013. Br J Sports Med 2013;47:1003-11.

4 Ferguson A. Injuries in Australian rules football. Ann Gen Pract 1965:155-61.

5 Stanitski CL, McMaster JH, Ferguson RJ. Synthetic turf and grass: a comparative study. J Sports Med 1974:2:22-6.

6 Nicholas JA, Rosenthal PP, Gleim GW. A historical perspective of injuries in professional football. Twenty-six years of game-related events. JAMA 1988;260:939-44.

7 Seward HG, Patrick J. A three year survey of Victorian football League injuries. Aust J Sci Med Sport 1992;24:51-4

8 de Loës M, Goldie I. Incidence rate of injuries during sport activity and physical exercise in a rural Swedish municipality: incidence rates in 17 sports. Int I Sports Med 1988:9:461-7.

9 Ekstrand J, Gillquist J, Möller M, et al. Incidence of soccer injuries and their relation to training and team success. Am J Sports Med 1983;11:63-7.

10 Powell JW. Incidence of injury associated with playing surfaces in the National football League 1980-1985. Athl Train 1987;22:202-6.

11 Ekstrand J, Healy JC, Waldén $\mathrm{M}$, et al. Hamstring muscle injuries in professional football: the correlation of MRI findings with return to play. Br I Sports Med 2012:46:112-7.

12 Agre JC. Hamstring injuries. proposed aetiological factors, prevention, and treatment. Sports Med 1985;2:21-33.
13 Elliott MCCW, Zarins B, Powell JW, et al. Hamstring muscle strains in professional football players: a 10-year review. Am J Sports Med 2011;39:843-50.

14 Ahmad CS, Dick RW, Snell E, et al. Major and minor League baseball hamstring injuries: epidemiologic findings from the major league baseball injury surveillance system. Am J Sports Med 2014;42:1464-70.

15 Roberts SP, Trewartha G, England M, et al. Epidemiology of time-loss injuries in English community-level rugby Union. BMJ Open 2013;3:e003998.

16 Lindenfeld TN, Noyes FR, Marshall MT. Components of injury reporting systems. Am J Sports Med 1988; 16:569-80.

17 Noyes FR, Lindenfeld TN, Marshall MT. What determines an athletic injury (definition)? Who determines an injury (occurrence)? Am J Sports Med 1988;16(Suppl 1):S65-8.

18 Levy IM. Formulation and sense of the NAIRS athletic injury surveillance system. Am J Sports Med 1988;16(Suppl 1):S132-3. S201-21.

19 Seward $\mathrm{H}$, Orchard J, Hazard $\mathrm{H}$, et al. Football injuries in Australia at the élite level. Med J Aust 1993;159:298-301.

20 Orchard J. Orchard sports injury classification system (OSICS). Sport Health 1993:11:39-41.

21 Orchard J. Orchard Sports Injury Classification System (OSICS). In: Bloomfield J, Fricker P, Fitch K, eds. Science and medicine in sport. 2nd edn. Melbourne: Blackwell, 1995: 674-81

22 Rae K, Orchard J. The orchard sports injury classification system (OSICS) version 10. Clin J Sport Med 2007;17:201-4.

23 Bahr R, Clarsen B, Derman W, et al. International Olympic Committee consensus statement: methods for recording and reporting of epidemiological data on injury and illness in sport 2020 (including STROBE extension for sport injury and illness surveillance (STROBE-SIIS)). Br J Sports Med 2020;54:372-89.

24 Derman W, Schwellnus MP, Jordaan E, et al. Sport, sex and age increase risk of illness at the Rio 2016 summer Paralympic games: a prospective cohort study of 51198 athlete days. Br J Sports Med 2018;52:17-23.

25 Mountjoy M, Junge A, Alonso JM, et al. Consensus statement on the methodology of injury and illness surveillance in FINA (aquatic sports). $\mathrm{Br}$ I Sports Med 2016;50:590-6.

26 Pluim BM, Fuller CW, Batt ME, et al. Consensus statement on epidemiological studies of medical conditions in tennis, April 2009. Clin J Sport Med 2009;19:445-50.

27 Timpka T, Alonso J-M, Jacobsson J, et al. Injury and illness definitions and data collection procedures for use in epidemiological studies in athletics (track and field): consensus statement. Br J Sports Med 2014;48:483-90.

28 Weir A, Brukner P, Delahunt E, et al. Doha agreement meeting on terminology and definitions in groin pain in athletes. Br J Sports Med 2015;49:768-74. 


\section{Correction: Sport Medicine Diagnostic Coding System (SMDCS) and the Orchard Sports Injury and IIIness Classification System (OSIICS): revised 2020 consensus versions}

Orchard JW, Meeuwisse W, Derman W et al. Sport Medicine Diagnostic Coding System (SMDCS) and the Orchard Sports Injury and Illness Classification System (OSIICS): revised 2020 consensus versions. Br J Sports Med 2020;54:397-401. doi: 10.1136/bjsports-2019-101921.

Prof Wayne Derman has had the incorrect affiliation included on his paper.

The correct affiliations should be:

Institute of Sport and Exercise Medicine, Department of Surgical Sciences, Stellenbosch University, Cape Town, South Africa

International Olympic Committee Research Centre, Cape Town, South Africa

(C) Author(s) (or their employer(s)) 2021. No commercial re-use. See rights and permissions. Published by BMJ.

Br J Sports Med 2021;55:e1. doi:10.1136/bjsports-2019-101921corr1

Check for updates 